\title{
Privilegio académico y escolasticismo moderno: trascendencia secular e inmanencia mundana ${ }^{*}$
}

\section{天 \\ Academic Privilege and Modern Scholasticism:} Secular Transcendence and Wordly Immanence

\author{
Saurabh Dube \\ El Colegio de México \\ México \\ Correo: saurabhdube99@gmail.com \\ https://orcid.org/0000-0002-4766-4694 \\ DOI: 10.48102/hyg.vi57.374
}

Artículo recibido: 27/08/2020

Artículo aceptado: I3/02/202I

\section{Abstract}

This essay explores issues of worldly immanence and secular transcendence by focusing on modern scholasticism. Such scholasticisms intimate pervasive procedures that turn their particular case into the general story while forgetting the conditions that make this possible. It is exactly such spectacular conjuring that the essay refers to as secular transcendence: implicit assumptions of immaculate knowledge that occlude and ignore the traces and tracks of its maculate birth in the world. Against this is contrasted the presence of worldly immanence, which militates against routine assumptions of the disenchantment of -and detachment toward- the world. Seizing upon such worldly immanence, the essay critically explores how modern scholasticism and secular transcendence formidably beget and betoken the cultural privilege of academic arenas, embodied at once in the latter's conceptual conventions as well as their everyday life-worlds.

Key words: Immanence, Scholasticism, Public Sphere, Jürgen Habermas, Academic-Privilege.

* Este ensayo se redactó originalmente en inglés. Para enriquecer la lectura, Historia y Grafía publica las dos versiones. 


\section{RESUMEN}

Este ensayo explora las cuestiones de la inmanencia mundana y la trascendencia secular centrándose en la escolástica moderna. Dicha escolástica emplea procedimientos omnipresentes que convierten su caso particular en historia general, olvidando las condiciones que lo hacen posible. Es exactamente esa espectacularidad la que el ensayo denomina trascendencia secular: suposiciones implícitas de un conocimiento inmaculado que ocluye e ignora las huellas y rastros de su nacimiento maculado en el mundo. Frente a esto se contrapone la presencia de la inmanencia mundana, que milita contra los supuestos rutinarios del desencanto de -y el desapego hacia- el mundo. Aprovechando esa inmanencia mundana, el ensayo explora de manera crítica cómo la escolástica moderna y la trascendencia secular engendran y denotan formidablemente el privilegio cultural de los ámbitos académicos, encarnado a la vez en las convenciones conceptuales de estos últimos, así como en sus mundos vitales cotidianos.

Palabras clave: inmanencia, escolasticismo, esfera pública, Jürgen Habermas, privilegio académico.

E ensayo que se presenta a continuación es una especie de mosaico que cose, superpone y une motivos comunes de la vida académica con preguntas críticas formuladas de modo poco habitual. Aquí me centro sobre todo en consideraciones sobre la inmanencia (cotidiana) y la escolástica (moderna). Sin embargo, al hacerlo, por fuerza recurro a algunos atributos de lo analítico y lo afectivo, así como a cuestiones de derecho e investigación. Se trata de afirmar la presencia en el mundo de estos conceptos-entidades y de desentrańar su constitución y relevancia en el ámbito académico. De esta forma, planteo preguntas relativas a la inmanencia mundana y a la trascendencia secular, a la escolástica moderna y al privilegio académico en nuestra época.

Hay razones de peso para emprender estas tareas. A lo largo de más de tres décadas, mis investigaciones, escritos y enseñanzas han combinado la historia, la antropología y la teoría social, 
centrándose principalmente en temas de procedencia sudasiática, pero siempre poniéndolos en diálogo con otros terrenos geopolíticos, en especial con América Latina. Al mismo tiempo, siempre he abordado estas cuestiones en términos de consideraciones más amplias de pensamiento crítico y teoría, y sobre la prudencia de metodologías y métodos. ${ }^{1} \mathrm{Al}$ hacerlo, he encontrado, una y otra vez, formidables "excepcionalismos" que abundan en la academia, particularmente en el estudio de Asia y África (pero también de América Latina, incluyendo México).

Por un lado, estos ámbitos han sido presentados a menudo como innatamente diferentes y demasiado distantes, portadores de un exotismo innato o que encarnan una carencia inevitable (o ambas cosas a la vez): imaginados a semejanza de la historia universal, reflejados en los espejos de la modernidad euroamericana, reproduciendo siempre sus conjunciones jerárquicas de tiempo y espacio. Por otro lado, los desafíos a tales tendencias, ya sea como pensamiento antiesencialista o como crítica poscolonial y decolonial, han elaborado una especie distinta de excepcionalismo: ahora, la fuerza de la crítica convierte el poder -del imperio y de la nación, de la colonia y de la modernidad, del Estado y de Occidente- en una totalidad distópica contra la que se enfrenta la ética de la alteridad y la subalternidad, la inocencia de la diferencia y la resistencia, cada una articulada como particularidades no recuperadas, antídotos a priori de la autoridad. ${ }^{2}$ Aquí, ambos bandos pasan por alto sus propias pretensiones de trascendencia intelectual y la presencia contrastada de imaginarios radicales de inmanencia apremiante. Permanecer en tales tendencias y pensar más allá de ellas es evitar con decisión los excepcionalismos -incluidos los de Asia, África y América Latina- para dejar entrar en

\footnotetext{
${ }^{1}$ Estas tendencias gemelas recorren mis diferentes trabajos citados en este ensayo. Se plasman con agudeza en Saurabh Dube, El archivo y el campo: Antropologia, historia, modernidad.

${ }^{2}$ Vid. especialmente, Saurabh Dube, Subjects of Modernity: Time-Space, Disciplines, Margins.
} 
su lugar los protocolos de distintas tradiciones de la teoría social, basados no en sus orígenes metageográficos sino en sus posibilidades críticas. En otras palabras, no hay modo de alejarse de la insuficiencia formativa, la indispensabilidad y la no unicidad de Europa y Occidente, de la modernidad y de sus márgenes -no al menos de forma meramente empírica, sino de forma imaginativamente crítica-.

\section{Comienzos}

Frente a estos desafíos, este ensayo explora las cuestiones de la inmanencia mundana al mismo tiempo que cuestiona el incesante clamor de una trascendencia secular. En este sentido, cabe destacar que la trascendencia y la inmanencia suelen entenderse en relación con lo divino, a partir de la antinomia entre lo religioso y lo secular, o de la oposición entre el encantamiento y el desencanto en/del mundo. Como pronto quedará claro, al cuestionar tales antinomias mi énfasis está en una inmanencia mundana, que no se predica sobre lo divino. ${ }^{3}$ Igualmente, al hablar de trascendencia, siempre en relación con la escolástica, mi referencia es a los supuestos de conocimiento inmaculado que ocluyen e ignoran las huellas y rastros de su nacimiento maculado en el mundo. En cierto sentido, pues, la pregunta más amplia que planteo es la siguiente: al articular los mundos de hoy y de ayer, ¿puede nuestro esfuerzo descansar en una aceptación de la inmanencia mundana, en lugar de buscar los requisitos de la trascendencia secular?

En este punto vale la pena detenerse un poco más en los términos "escolasticismo" y "trascendencia secular", que se engendran uno al otro. Ahora bien, la escolástica se refiere por lo común al sistema y método de enseñanza y aprendizaje de la teología y la filosofía que predominó en Europa desde el siglo XII hasta el XVI.

${ }^{3}$ Vid. infra especialmente la sección: "Desmadejar la inmanencia". 
De hecho, el término fue inventado por los humanistas renacentistas del XVI para describir peyorativamente la verborrea estilística y el intelectualismo estéril de tales tendencias. ${ }^{4} \mathrm{Al}$ mismo tiempo, basándome ante todo en la obra de Pierre Bourdieu, y uniéndola a los planteamientos de Jacques Rancière, mi uso de la escolástica tiene un alcance más amplio..$^{5}$ Dicho de modo simple, se refiere a las orientaciones y comprensiones en el pasado y en el presente que convierten su caso particular en la historia general, olvidando las condiciones que lo hacen posible.

Expresado de otra forma, las escolásticas modernas atraviesan diferentes orientaciones ideológicas, y prácticas políticas distintas, como parte de su aprehensión, objetivación y actuación sobre el pasado, el presente y el futuro. Lo que es común a todas ellas es el privilegio formativo de su propio "debería" por sobre las afirmaciones rotundas, o el "es" exacto, de mundos contradictorios, dejando asiduamente de lado a los sujetos históricos también contendientes. Es justo esta espectacular conjura a la que me refiero como trascendencia secular. ${ }^{6}$ Ahora bien, los protocolos escolásticos de trascendencia secular existen como disposiciones y estructuras -o, como disposiciones estructuradas- que no son sólo académicas, meramente intelectuales, simplemente filosó-

${ }^{4}$ En este caso, como ha demostrado Josef Pieper, estas valoraciones preparadas merecen un examen más detallado, aunque también es importante rastrear, siguiendo a Orlando Bentancor, cómo la presunción escolástica podría estar implicada en proyectos más amplios de poder y significado, como los de los procesos imperiales y el capitalismo mercantil. Josef Pieper, Scholasticism: Personalities and Problems of Medieval Philosophy; Orlando Bentancor, The Matter of Empire: Metaphysics and Mining in Colonial Perú.

${ }^{5}$ Pierre Bourdieu, Pascalian Meditations; Jacques Rancière, The Philosopher and His Poor; Vid. también, Pierre Bourdieu, Distinction: A Social Critique of the Judgement of Taste; Jacques Rancière, The Nights of Labor: The Workers' Dream in Nineteenth-Century France; y Jacques Rancière, The Ignorant Schoolmaster: Five Lessons in Intellectual Emancipation.

${ }^{6}$ Bert van Roermund ofrece una visión distinta de la "trascendencia secular", que intrigantemente se cruza con aspectos de mi propuesta sobre la trascendencia. Bert van Roermund, "Kelsen, Secular Religion, and the Problem of Transcendence". 
ficas. En realidad, estos procedimientos son mundanos en gran escala. Encarnan y engendran el derecho, el privilegio y la jerarquía de argumentos y de análisis, de palabras y de mundos.

Elaborando estas proposiciones, mi esfuerzo por delante es ni más ni menos que desentrañar tales escolasticismos y sus implicaciones, explorando a la vez las convenciones conceptuales y los mundos de la vida cotidiana de la academia. Se trata de emprender estas tareas para rastrear cómo el heterogéneo pero inmaculado "deber" de la escolástica -y sus constantes afirmaciones de trascendencia secular- engendran y denotan formidablemente el privilegio cultural de los ámbitos académicos. En conjunto, el ensayo teje los motivos, diseños y patrones de las omnipresentes proyecciones de la trascendencia secular, la formidable presencia del razonamiento escolástico, el incesante lugar del derecho cultural, y las silenciosas posibilidades de la inmanencia mundana.

\section{Puntadas iniciales}

En lo que se refiere a cuidadoso(s) cuestionamiento(s) del conocimiento moderno como ligado a la afirmación imaginativa de los mundos sociales, de lo que se trata es de las formas en que los escenarios académicos y cotidianos se unen y se separan. Es decir, en lugar de poner entre paréntesis y proteger los argumentos intelectuales de los mundos más amplios en los que están integrados, estas afirmaciones y concepciones deberían someterse una y otra vez a los exigentes términos de los terrenos cotidianos, incluyendo las insinuaciones mutuas de poder y significado, autoridad y alteridad, lo dominante y lo subalterno en estos dominios.

Basándome en estas disposiciones -a la vez que entrelazo los impulsos analíticos con las sensibilidades hermenéuticas- mi propio esfuerzo ha distinguido entre los "sujetos de la modernidad" históricamente situados como portadores de razones/comprensiones heterogéneas, por un lado, y las representaciones rutinarias 
del "sujeto moderno" como insinuación de una racionalidad singular, por otro. En realidad, la distinción se encuentra en el centro de mi comprensión de la modernidad, a la que me acerco no nada más como una idea, un ideal, una ideología, sino como procesos históricos de significado y poder que se remontan a los últimos cinco siglos. Para explicar mejor los argumentos de este ensayo, es imprescindible hacer un pequeño desvío.

Para empezar, según mi lectura, la modernidad no es el único producto de, por ejemplo, las dualidades cartesianas o una Ilustración singular predicada sobre el engrandecimiento de la analítica o los esfuerzos imperiales de los británicos, los franceses y los holandeses después del siglo XviII o, de hecho, todo lo anterior. Más bien, la modernidad de la Ilustración (con su aguda interacción entre raza y razón) llegó sólo después de la modernidad del Renacimiento (con su entrelazamiento de instrumentalismo metafísico y capitalismo mercantil), al igual que la violencia constitutiva de la modernidad de los colonialismos posteriores fue precedida por los genocidios modernos de los imperios de una Espańa anterior y un Portugal anterior. La cuestión es que -a diferencia de la heterogeneidad innata y las contenciones formativas de la Ilustración de los siglos XVII y XVIII- los procesos de la modernidad desde el XVI deben ser abordados como constitutivamente contradictorios.?

${ }^{7}$ Cabe destacar que mi propia comprensión accede a los trabajos recientes sobre la modernidad que han trazado nuevas direcciones, pero también los supera. Tales desviaciones han servido para poner en primer plano las cuestiones de la modernidad en las agendas académicas y en los horizontes intelectuales, con mayor amplitud. Indico aquí cuatro tendencias críticas. En primer lugar, ha habido trabajos que se han centrado en diferentes expresiones de lo moderno y en distintas articulaciones de la modernidad como algo históricamente fundamentado y/o culturalmente expresado, articulaciones que cuestionan las proyecciones a priori y los formalismos sociológicos que sustentan la categoría-entidad. En segundo lugar, están los estudios que han explorado de forma diversa las cuestiones de la modernidad/modernidad "temprana" y "colonial” y "múltiple" y "alternativa", incluso como parte de las "historias conectadas". En tercer lugar, encontramos imaginativas exploraciones etnográficas, históricas y teóricas de los afines conceptuales de la modernidad, como la globalización, el capitalismo y el 
Por un lado, como parte de un cuadro conocido, hacen la modernidad los procesos de la razón y la ciencia, la industria y la tecnología, el comercio y el consumo, la ciencia y el descubrimiento, el Estado-nación y el ciudadano-sujeto, las esferas públicas y los espacios privados, y la(s) religión(es) seculariza$\mathrm{da}(\mathrm{s})$ y el(los) conocimiento(s) desencantado(s). En este sentido, cabe destacar que es necesario estar vigilante ante el despliegue interminable de estos desarrollos como historias inexorables y heroicas. De hecho, tales historias requieren ser desentrañadas como narrativas bastante más accidentadas. Por otro lado, en el núcleo de la modernidad se encuentran procesos de imperios y colonias, razas y genocidios, literalismos y escolasticismos, fes resurgentes y tradiciones reificadas, regímenes disciplinarios y sujetos subalternos, seducciones del Estado y encantos de lo moderno. Estas dos vertientes de la modernidad no se separan sino que se entrelazan entre sí. Se trata de registrar que los procedimientos de la modernidad han sido contradictorios, contingentes y contestados -protocolos que se articulan sin cesar pero que también están críticamente desarticulados entre sí-.

Ahora bien, son justo estos procedimientos los que emergen expresados por los sujetos de la modernidad. Me refiero aquí a los actores históricos que han participado con asiduidad en los procesos de la modernidad: actores sociales que han estado sujetos a estos procesos, pero han sido también sujetos configuradores de los mismos. En los últimos siglos, los sujetos de la modernidad han

cosmopolitismo, así como de las cuestiones relacionadas con el Estado, la nación y la democracia. En cuarto y último lugar, se han realizado diversas exploraciones de los encantos de la modernidad y de la magia de lo moderno, entendidos no como errores analíticos sino como formadores de mundos sociales. Estos estudios han abarcado desde las elaboraciones del fetiche del Estado, el carácter sagrado de la soberanía moderna, lo siniestro del capitalismo y los encantos rutinarios de la modernidad hasta la magia secular de las prácticas de representación como los espectáculos de entretenimiento, el cine y la publicidad. Estas cuestiones críticas y estas tendencias más amplias se analizan en las referencias de la siguiente nota. 
incluido, por ejemplo, a los campesinos, artesanos y trabajadores del sur de Asia que han articulado de forma diversa los procesos de colonia y poscolonia; a las comunidades indígenas de las Américas bajo el dominio colonial y nacional; a los pueblos de ascendencia africana no sólo en ese continente, sino en diferentes diásporas de todo el mundo; y, de hecho, a las mujeres y hombres subalternos, marginales, de clase media y de elite en los escenarios no occidentales y occidentales. No es de extrañar que estos sujetos hayan registrado en sus medidas y significados las contradicciones, conflictos y contingencias formativas de la modernidad. ${ }^{8}$

La distinción entre el sujeto moderno, definido exclusivamente, y los sujetos por fuerza heterogéneos de la modernidad, es importante, tanto desde el punto de vista histórico como teórico. ${ }^{9}$ En realidad, es destacada de modo especial para pensar en una razón de sentido omnipresente, legislativa y adjudicadora, que abunda en la academia y que, por supuesto, se extiende mucho más allá. De hecho, dicha racionalidad (y razón) enmarca los objetos que estudia en la imagen de la razón singular y propia del comentarista-analista, en lugar de como sujetos de otras razones, lo que conlleva igualmente cuestiones de derecho y privilegio, afecto y concreción corporal. ${ }^{10}$

${ }^{8}$ Dube, Subjects of Modernity, op. cit.; y Saurabh Dube, Stitches on Time: Colonial Textures and Postcolonial Tangles. Vid. también, Saurabh Dube (ed.), Enchantments of Modernity: Empire, Nation, Globalization; Saurabh Dube e Ishita Banerjee-Dube (eds.), Unbecoming Modern: Colonialism, Modernity, Colonial Modernities; y Saurabh Dube (ed.), Modern Makeovers: Handbook of Modernity in South Asia.

${ }^{9}$ De hecho, nada de esto es a la pluralidad formativa, la no-unidad también constitutiva de los sujetos modernos que son ellos mismos siempre también sujetos de modernidad. Vid., por ejemplo, Dube, Subjects of Modernity, op. cit., y también la conversación entre Carlos Marichal y Saurabh Dube disponible en: $<$ https://www.youtube.com/watch?v=2lfYucKbL8Y\&feature=emb_logo $>$.

${ }^{10}$ Todas estas son cuestiones que he tratado de forma frontal e incipiente en otros lugares: Dube, Subjects of Modernity, op. cit.; Dube, Stitches on Time, op. cit:; y Saurabh Dube, After Conversion: Cultural Histories of Modern India. 
El presente ensayo lleva adelante estas preocupaciones al narrar la presencia omnipresente de distintos escolasticismos -que implican la sustitución de cualquier "es" conflictivo por su correspondiente "debería" - tanto en los mundos académicos como cotidianos. De hecho, exploro cómo estas tendencias están ligadas a formidables concepciones de la creación de conocimiento que se fundan de forma diversa en términos de trascendencia, seculares pero proféticos, que vienen a perseguir incluso a aquellas ofertas que intentan escapar de ellas. A lo largo de todo el texto, intentaré desentrañar, aunque a menudo de forma implícita, el lugar de una inmanencia mundana -ligada a su vez a texturas de afecto y encarnación, a formaciones de lo sensual y lo políticocomo medio de acercarse y comprender el pasado y el presente. Al final, reuniré estas consideraciones articulando de nuevo mi propuesta anterior (hecha por primera vez hace casi dos décadas) de una "historia sin garantía".

Está claro que este ensayo se centra en una pregunta sobre las prerrogativas de la escolástica, en especial sobre el inmaculado deber que implica y a la vez traiciona, en el ámbito académico. En este caso, me planteo la academia como un escenario cultural y políticamente estratificado, constituido por distintas formaciones de privilegio y jerarquía, con sus derechos y sus cuestionamientos, que giran, por ejemplo, en torno al género y la casta, la clase y la raza, el estatus y la sexualidad. Por lo tanto, los ámbitos académicos pueden considerarse más bien como campos etnográficos, situados en el espacio-tiempo, siempre parte de mundos sociales con sus propias culturas cotidianas, en los que los académicos trabajan pero también viven. Las expresiones y prácticas de los sujetos académicos, en particular las del observador, en los espacios académicos cotidianos - por ejemplo, seminarios, cafés, librerías y redes sociales- pueden ser muy reveladoras en este sentido. Esas palabras rutinarias y esos gestos reflejos a menudo revelan suposiciones y afectos más amplios, derechos y experiencias de los terrenos intelectuales. No es de extrañar que, a pesar del constante 
clamor de que los argumentos académicos no están contaminados por los mundos cotidianos, las afirmaciones certificadas dentro de la academia también estén acechadas por lo mundano, sus perversiones y posibilidades.

De hecho, la cuestión podría ser justo no separar la suposición cotidiana y la expresión acreditada del esfuerzo intelectual. Porque, en conjunto, lo que está en juego son las orientaciones y los argumentos no dichos, subdichos y ya dichos que sustentan la vida y la comprensión dentro de las culturas académicas. En las páginas que siguen, exploro a la vez las manifestaciones cotidianas y las expresiones autorizadas de los ámbitos académicos. De este modo, también planteo, necesariamente de forma implícita, los términos más amplios del privilegio y su cuestionamiento en los mundos sociales, que los ámbitos académicos encarnan y en los que están incrustados, aunque, por supuesto, a su estilo.

\section{DesmadeJar la INMANENCIA}

Mis argumentos tienen como trasfondo las disposiciones superpuestas de las categorías académicas y los mundos sociales. Esto nos lleva a preguntarnos: ¿qué entiendo por inmanencia? Para empezar, esto es lo que opongo a la inmanencia: la visión generalizada del mundo como "desencantado", de manera que se pretende extirpar, e incluso exorcizar, el lugar que tienen en este mundo "las propiedades de valor (buenas o malas, hostiles o benignas) que nos plantean exigencias normativas". ${ }^{11}$ No hace falta decir que esta visión ha desempeñado un papel central también en la concepción del mundo "como algo ajeno a nuestra sensibilidad de compromiso práctico, [...] algo que debe estudiarse de forma independiente o, cuando se trata de un compromiso práctico, algo ajeno, que debe dominarse, conquistarse y controlarse

${ }^{11}$ Akeel Bilgrami, "Understanding Disenchantment". 
para nuestra utilidad y beneficio". ${ }^{12}$ Ahora, cuestiono la presunción de tal distanciamiento y afirmo, en cambio, estar abierto "no en exclusiva a las palabras en nuestras páginas y en nuestros labios y no sólo a las imágenes en nuestros lienzos, sino [a] los objetos y las cosas en el mundo, incluso en la naturaleza, [que] están llenos de propiedades de valor y significado". ${ }^{13}$

Al mismo tiempo, sin embargo, sostengo también que los términos y las texturas del desencanto llevan sus propios encantos, que

se extienden desde los orígenes y fines inmaculadamente imaginados de la modernidad hasta la densa magia del dinero y los mercados; y desde las novedosas mitologías de la nación y el imperio hasta las oposiciones jerárquicas entre mito e historia, emoción y razón, ritual y racionalidad, Oriente y Occidente, y tradición y modernidad. Intensamente espectrales pero concretamente palpables, formando representaciones tangibles e informando de prácticas contundentes, las unas ligadas a las otras, estos encantos acechan a los mundos del hacer y deshacer de la modernidad. Los encantos de la modernidad dan forma al

${ }^{12}$ Idem.

${ }^{13}$ Akeel Bilgrami, Secularism, Identity, and Enchantment, p. 183. Pronto debería quedar claro que, si bien estoy de acuerdo con Bilgrami en las "propiedades de valor" del mundo (incluida la naturaleza) que nos plantean exigencias normativas, mis argumentos tienen igualmente un énfasis distinto. Así, Bilgrami considera que el "desencanto" ha sido el motivo dominante del mundo moderno en los últimos cuatro siglos. En contra de esto, postula las fuerzas creativas del "encanto" y su reconocimiento -por parte de las sectas radicales inglesas del siglo XVII, los románticos y Gandhi, por ejemplo-, de manera que el poder se opone/ deshace por la diferencia. Yo me centro, en cambio, también en cómo los términos del desencanto crean sus propios encantos, que encuentran forma y asumen sustancia como antinomias y tentaciones, categorías y contenciones, significados y prácticas en el núcleo de los mundos sociales. Éstos llegan a encarnar propiedades de valor que reclaman a los sujetos y a sus acciones. De ello se desprende que mi propuesta sobre la inmanencia se basa en lo afectivo, lo encarnado, lo experiencial y lo extraanalítico como señal de lo inmanente como parte rutinaria de lo mundano. Podría decirse que Bilgrami no se ocupa especialmente de esas dimensiones de los encantos del desencanto y la inmanencia de lo cotidiano. 
pasado y al presente ordenando y orquestando estos terrenos, a la vez temporal y espacialmente. ${ }^{14}$

Esta ordenación y orquestación van mucho más allá de la mera observación del mundo. Más bien, nos encontramos ante procesos poderosos, integrados en proyectos omnipresentes de significado y poder, que nombran y objetivan los mundos para reelaborarlos y rehacerlos. En este caso, las antinomias y tentaciones de la modernidad se convierten en estructuras de sentimiento y atributos de la experiencia en la vida de los sujetos. Al estar hechas del mundo -es decir, formidablemente mundificadas- estas oposiciones y encantamientos adquieren con agudeza propiedades de valor, que invitan e incitan a la acción y a la contención. Como pronto veremos, lo afectivo, lo encarnado y lo extraanalítico, lo cotidiano y lo mundano, todos ellos temas/formas de inmanencia, que se despliegan en registros/tejidos distintos, tienen aquí una enorme importancia.

Para empezar, las afirmaciones que cuestiono en este ensayo no se tratan como aberraciones ideológicas y prácticas erróneas, ni se presentan como meros objetos de conocimiento, atributos independientes de los mundos sociales, a la espera de una simple confirmación o una pronta refutación. Por el contrario, se abordan como estipulando y apuntalando los mundos que habitamos, de manera que estos significados y prácticas aparezcan como condiciones de conocimiento, insinuando formas de ser que requieren una articulación cuidadosa y crítica. Esto significa además desistir de definir tales proposiciones y posiciones como esfuerzos principalmente cerebrales-cognitivos. Se trata de registrar más bien sus densas dimensiones mundanas, que no sólo nombran el mundo sino que trabajan sobre el mundo para rehacerlo. ¿Es posible que esto dé otro giro a la necesidad de pensar en las categorías analíticas de procedencia académica, poniéndolas en relación con las

${ }^{14}$ Dube, Subjects of Modernity, op. cit., p. 64. 
configuraciones cotidianas de los terrenos que describen, y con los requisitos resueltos de los mundos inmanentes? ¿Puede hacerse esto no privilegiando ni lo uno (lo académico o intelectual) ni lo otro (lo cotidiano o mundano), sino desentrańando en plan vigilante ambos en vista de su articulación crítica, sin perder de vista la idea del radical Durkheim de que es en los mundos rutinarios (quizá de inmanencia) donde se imagina lo inimaginable?

Y hay más a considerar. Porque, al abordar y comprender los escenarios académicos y cotidianos, podría ser fundamental permanecer más tiempo con las formas corpóreas, afectivas y sensoriales de experimentar/saber/ser. ${ }^{15}$ Éstas cuestionan las presunciones generalizadas y persistentes de los sujetos en su totalidad fabricados - poseídos por una razón ya-consumada-, pero sin ser presociales en ningún sentido, ya que se derivan de mundos vitales inmanentes necesariamente heterogéneos, pero cada vez más superpuestos. Dicho de otro modo, ¿pueden las apreciaciones de la vida social evitar comenzar con el "sujeto intencional delimitado y, al mismo tiempo, poner en primer plano la encarnación y la vida sensual"? ${ }^{16}$ En tal caso, ¿podrían las "circunstancias afectivas" tomar precedencia experimental por sobre los procedimientos más formales de la razón, a la vez que serles constitutivamente coetáneos? De hecho, con el "sujeto y el sentido" conformados por elementos de la experiencia, ${ }^{17}$ ¿podríamos también seguir el ejemplo de Gadamer -que articula, por supuesto, una tradición intelectual distinta- para preguntarnos: cómo podríamos abrirnos a la conciencia de "estar expuestos a las labores de la historia" que "preceden a las objetivaciones de la

${ }^{15}$ Sara Ahmed, The Cultural Politics of Emotion; Patricia Ticineto Clough y Jean Halley (eds.), The Affective Turn: Theorizing the Social; Kathleen Stewart, Ordinary Affects; Vid. también Saba Mahmood, Politics of Piety: The Islamic Revival and the Feminist Subject; y W. J. T. Mitchell, What do Pictures Want? The Lives and Loves of Images.

${ }^{16}$ William Mazzarella, "Affect: What is it Good for?", p. 291.

${ }^{17}$ John Rajchman, “Introduction”, p. 15. 
historiografía documental" y a la antropología explicativa. ${ }^{18}$ Sin duda, no estoy hablando de lo afectivo y lo extraanalítico, cada uno siempre encarnado, como una especie de "retorno de lo reprimido", bajo la modernidad. ${ }^{19}$ Más bien me refiero a lo afectivo, lo extraanalítico y lo encarnado como algo rutinario entretejido en nuestros mundos modernos cotidianos y académicos, cada uno de ellos anunciando siempre, pues... la inmanencia. ${ }^{20}$ ¿Cómo podrían estos atributos inmanentes de la vida social -incluyendo el lugar y el juego de la añoranza y la pérdida, el color y el olor, lo sensible y lo sensual-ser incorporados a las descripciones, tejidos en las narrativas, en lugar de perseguir lo que se ha llamado una "ciencia sin sentido"?21

\section{Tema uno}

Poco después de los atentados del 11-S en Nueva York, el teórico político Craig Calhoun estuvo en Ciudad de México. En El Colegio de México, Craig se centró en el "cosmopolitismo realmente existente" como "visión desde la sala de viajeros frecuentes", planteando una serie de cuestiones críticas. Sobre todo, sugirió que

El 11 de septiembre [de 2001], los terroristas que estrellaron aviones contra el World Trade Center y el Pentágono [...] precipitaron una renovación de la política centrada en el Estado y una "guerra contra el terrorismo" que buscaba soluciones mili-

\footnotetext{
${ }^{18}$ Hans-Georg Gadamer apud Zygmunt Bauman, Intimations of Postmodernity, pp. ix-x.

${ }^{19}$ Mazarella, "Affect", op. cit., p. 293.

${ }^{20}$ Debería ser evidente que estoy reuniendo una serie de argumentos diferentes derivados de distintas tradiciones de comprensión. Las superposiciones y tensiones entre sus supuestos y énfasis exigen una mayor permanencia y reflexión crítica, que no puedo desarrollar aquí.

${ }^{21}$ Johannes Fabian, Out of Our Minds: Reason and Madness in the Exploration of Africa, p. ix.
} 
tares en lugar de policiales para el crimen. [...] No hace falta ser amigo del terrorismo para lamentar que la respuesta dominante a los ataques terroristas se haya enmarcado como una cuestión de guerra más que de crimen, un ataque a Estados Unidos más que un ataque a la humanidad [...] El militarismo ganó y la sociedad civil perdió [...] cuando las administraciones de Estados Unidos y de otros países se movieron para barrer las protecciones de los derechos de los ciudadanos y de los inmigrantes por igual, y fortalecer el estado en pos de la "seguridad". ${ }^{22}$

Calhoun exploró luego los términos de este desafío al cosmopolitismo -a través de reivindicaciones sobre la tecnología, la economía y la ideología- cuyo propio impulso antioccidental revelaba un proyecto moderno contestatario, un antimodernismo estatista formador de la modernidad y sus contradicciones.

Todas ellas, provocaciones razonables, se supone, que nos invitan a permanecer y pensar a través de nuestras propias presunciones dadas por sentado sobre las imágenes y los mundos, especialmente girando sobre el cosmopolitismo y la modernidad, el Estado y el ciudadano, el Occidente y el no-Occidente. Sin embargo, lo que me preocupa aquí no son tanto los argumentos en sí como la respuesta que suscitaron. En el debate que siguió, una famosa antropóloga mexicana y burócrata cultural internacional, que parecía cada vez menos convencida a lo largo de la conferencia, sólo tenía una pregunta para el orador, al que conocía muy bien. “'Te has pasado al otro lado, Craig?”, preguntó con un aire de impaciente finalidad.

Al principio me sentí un poco desconcertado, pero a medida que la conversación continuaba fui comprendiendo lo que estaba en juego en la pregunta. El supuesto subyacente de la antropóloga interlocutora era que la alteridad y la autoridad tienen que ajustarse

${ }^{22}$ Craig Calhoun, "The Class-consciousness of Frequent Travelers: Toward a Critique of Actually Existing Cosmopolitanism". La presentación de Calhoun se derivaba de este texto. 
a la visión del analista sobre la diferencia y el poder, la tradición y la modernidad, lo no occidental y lo occidental, el otro y el yo. Ni que decir tiene que esta asunción analítica y extraanalítica estaba fundamentada a profundidad en el derecho y el privilegio -afectivo y experiencial- de la academia institucional y cotidiana, al que ya se ha aludido. ¿Dónde estaba la necesidad de cuestionar el cosmopolitismo, de registrar diferentes reivindicaciones sobre la tradición, de reconocer distintas visiones de la modernidad? Al fin y al cabo, ¿no se explican (siempre) estas cuestiones y (ya) se establecen a través de la presunción académica de cómo "debería" ser el mundo? Aquí se encuentra la formidable presunción de la escolástica dominante: un "debería" inmaculado del analista/ observador -académico o cotidiano- que triunfa sobre todo "es" contencioso. En la medida en que el "debería" orquesta y se convierte en el "es", los que no se alinean se pasan al "otro lado".

\section{DeSENREDAR LOS ESCOLASTICISMOS}

Los escolasticismos conllevan comprensiones y orientaciones que presentan su caso particular como la historia general, olvidando las condiciones que lo hacen posible: privilegian una visión desde algún lugar como la vista de todo el mundo; suscriben una racionalidad adjudicadora como la que anula todas las razones mundanas; universalizan el juicio ético y estético suprimiendo los campos socioeconómicos-culturales en los que tales juicios están incrustados; y aseguran su "debería" como el que cabalga sobre cada "es" que constituye el mundo. ${ }^{23} \mathrm{Ni}$ que decir tiene que todo

${ }^{23}$ Como ya he indicado, mis deudas con Bourdieu -junto con mi aprendizaje de Rancière- son inmensas en este caso. Dadas las limitaciones de espacio, lo que no puedo explorar son mis diferencias con Bourdieu, especialmente su frecuente formalismo y autoindulgencia cerebral, que pueden ir en contra de mis afirmaciones de lo afectivo, lo encarnado y lo inmanente. Bourdieu, Pascalian Meditations, op. cit.; Rancière, Philosopher and His Poor, op. cit.; Vid. también, 
esto subyace en las omnipresentes proclamas de trascendencia secular de la escolástica moderna.

Dichos escolasticismos y sus pretensiones trascendentales abundan en la academia, como piezas deliberadas de erudición y como expresiones rutinarias en su vida cotidiana, encarnando y respaldando con agudeza, acuñando y elaborando constitutivamente, el derecho, el privilegio y la jerarquía -en/como argumento, afecto y efecto-. De hecho, en el ejemplo del encuentro académico cotidiano que acabamos de relatar, los escolasticismos entran en juego de forma frontal, moviendo los brazos y mostrando los colmillos, por así decirlo. ${ }^{24}$

Todo esto es (relativamente) fácil de establecer y (sobre todo) poco exigente de reprender. Por lo tanto, paso a una tarea más difícil. En concreto, mi intento es desentrañar las formas en que la condición de posibilidad de la erudición destacada puede consistir en su trenzado entre persuasiones escolásticas -incluyendo la presencia y el triunfo del "debería" - y disposiciones bastante más conflictivas. Estas orientaciones distintas intentan acercarse y explicar los temas y los mundos en términos de sus mezclas y turbiedades mundanas, o el "es" contencioso que es la materia de la historia y la política, las palabras y los mundos, el pensamiento y la vida. Para ilustrar esto, permítanme recurrir - de forma poco convencional, para un historiador-antropólogo que habita distintas zonas fronterizas- a la obra del filósofo europeo Jürgen Habermas.

Mi locura tiene método.

Por un lado, las elaboraciones de Habermas sobre la razón como "acción comunicativa" y una modernidad autocrítica han ampliado los horizontes democráticos del proyecto "inacabado"

\footnotetext{
Bourdieu, Distinction, op. cit.; Rancière, Nights of Labor, op. cit.; y Rancière, The Ignorant Schoolmaster, op. cit.

${ }^{24}$ Tampoco es una cuestión exclusiva de los ámbitos intelectuales: los modos de argumentación académica se apropian, se expropian y se renuevan en terrenos sociales más amplios.
} 
de la Ilustración. ${ }^{25}$ Así, cuando el filósofo plantea la razón como "acción comunicativa", sus protocolos de argumentación desplazan a la vez una racionalidad meramente centrada en el sujeto y subrayan el "contradiscurso" de la modernidad. ${ }^{26}$ Anuncian cuestiones inmanentes de una racionalidad intersubjetiva, así como una obligación hacia el otro en la deliberación.

Por otro lado, estas tendencias en el pensamiento de Habermas están trabajadas a profundidad y, en consecuencia, marginadas por orientaciones distintas y superpuestas. En primer lugar, está el imperativo en sus esquemas del "deber" que está ligado a fondo a una razón escolástica. En segundo lugar, las proyecciones habermasianas de una "historia idealizada" presentan el pasado en términos de esquemas temporales modulares, que implican etapas de sucesión atenuadas. En tercer lugar, el filósofo asume un telos que se construye en el lenguaje en general. Por último, su equiparación de la modernidad con Europa, sostengo, tiene una procedencia extraanalítica, experiencial, e incluso afectiva.

En conjunto, mi punto de vista se refiere a los requisitos de meditar y pensar más allá de estas dimensiones contrastantes que son, sin embargo, disposiciones conjuntas en el pensamiento de Habermas. ${ }^{27}$ Y comienzo apropiadamente con la propuesta del

${ }^{25}$ Jürgen Habermas, The Philosophical Discourse of Modernity: Twelve Lectures.

${ }^{26}$ Jürgen Habermas, The Theory of Communicative Action; Habermas, The Philosophical Discourse, op. cit.; Jürgen Habermas, Postmetaphysical Thinking: Philosophical Essays; y Thomas McCarthy, "Introduction".

${ }^{27}$ Reconozco, por supuesto, que los escritos sobre Habermas y las discusiones sobre su obra son industria académica. Evidentemente, mi esfuerzo no pretende ser ni una exégesis ni un comentario sobre el corpus del filósofo. Más bien, deseo entrar en los protocolos de su pensamiento y su(s) razón(es), aunque en mis distintos registros, para revelar las puntadas contradictorias que suturan sus argumentos. Dichas contradicciones y contenciones no son meros errores, sino que se podría decir que son las condiciones de posibilidad de sus afirmaciones, cuestión que abordé por primera vez en Dube, After Conversion, op. cit.

En este sentido, cabe señalar que mi énfasis en las posibilidades y problemas simultáneos de la obra de Habermas se cruza con el involucramiento feminista con sus escritos. Dichos compromisos subrayan a la vez los horizontes democráticos sugeridos $y$, sin embargo, las exclusiones de género realizadas por lo si- 
filósofo del contradiscurso de la modernidad. Como es por lo general conocido, al menos para los iniciados, Habermas explora la encrucijada primaria de este contradiscurso para señalar un "camino abierto pero no tomado: la interpretación de la razón en términos de una intersubjetividad no coercitiva de entendimiento mutuo y reconocimiento recíproco" ${ }^{28}$ Aquí se encuentran formulaciones que ven la razón como ineludiblemente situada, es decir, "como concretada en la historia, la sociedad, el cuerpo y el lenguaje"; ven su potencial como algo que requiere ser realizado en la "práctica comunicativa de la vida ordinaria y cotidiana"; y, contra las críticas totalizadas de la razón, enfatizan su capacidad de ser crítica. ${ }^{29}$

$\mathrm{Al}$ mismo tiempo, debemos preguntarnos si tales medidas de Habermas reducen quizá las matrices de poder político a las relaciones de comunicación, ${ }^{30}$ lo que "devuelve subrepticiamente lo político al terreno de la ética”. ${ }^{31}$ Asimismo, ¿suprimen tales medidas los registros viscerales del ser y de la diferencia a un telos del lenguaje que proporciona el modelo para el discurso práctico y racional, uno que siempre tiende al consenso?32 Además, ¿qué

guiente: el relato de Habermas sobre la esfera pública; su teoría de la acción comunicativa; su teoría dualista de la sociedad; y sus debates sobre la democracia deliberativa. De éstos, discuto por delante los dos primeros temas, y me referiré allí a la crítica feminista sobre estas cuestiones. En este punto, me gustaría reconocer el astuto mapeo de esta literatura proporcionado por Mojca Pajnik en un ensayo que he leído con cierto esfuerzo en una traducción imperfecta. Mojca Pajnik, "Feminist Interpretations of the Public in Habermas's Theory (FEMINIsticne interpretacije jaVnosti v habermasovi teoriji)". Vid. también, Mojca Pajnik, "Feminist Reflections on Habermas's Communicative Action: The Need for an Inclusive Political Theory"; y Marie Fleming, "Women and the 'Public Use of Reason"”.

${ }^{28}$ McCarthy, "Introduction", op. cit., p. xvi.

${ }^{29}$ Ibidem, pp. xvi-xvii.

${ }^{30}$ Jürgen Habermas, Knowledge and Human Interests; y Habermas, Theory of Communicative Action, op. cit.

${ }^{31}$ Bourdieu, Pascalian Meditations, op. cit.; vid. también, Pierre Bourdieu, Language and Symbolic Power.

32 Stephen K. White, Sustaining Affirmation: The Strengths of Weak Ontology in 
debemos hacer con la crítica feminista de que la comprensión de Habermas de la acción comunicativa enfatiza una comprensión técnica de la racionalidad, que se abstrae de las particularidades de las formas no lingüísticas de la acción comunicativa y las deslegitima? ${ }^{33}$ Por último, ¿no se funden las propuestas de Habermas con su marco etnocéntrico de la racionalidad, que a su vez se apoya en su previa colusión experiencial de la modernidad con Europa? ¿Es esto lo que subyace a su concepción de la modernidad como un fenómeno europeo totalmente autogenerado, que ocluye cualquier vínculo con el imperio o los mundos no occidentales?

La cuestión es que registrar la declaración de Habermas sobre la naturaleza situada y crítica de la racionalidad es afirmar cómo su pensamiento puede abordar cuestiones de inmanencia, al menos cuando se expresa en distintos registros de lo mundano, lo teórico y su interacción. Sin embargo, para reconocer tales horizontes, la tarea de afirmación cuidadosa debe atender a las presunciones a priori del filósofo que revelan un "debería" trascendente, un escolasticismo formativo, así como la elisión extraanalítica de la modernidad con Europa: estas medidas circunscriben el "es" exacto que su pensamiento avala respecto a los atributos situados de la racionalidad. Tales medidas simultáneas son críticas para articular la inmanencia (pero sin convertirla en un horizonte de antídoto y utópico) mientras se rastrea la escolástica (pero sin tratarla como un enemigo distante y distópico), ya que la escolástica y la inmanencia son siempre del mundo, que nunca es inocente.

Esto me lleva al énfasis de Habermas en una comunidad de diálogo. Aquí, el filósofo respalda cómo, en la deliberación, el enunciado del otro pone una obligación en/para el yo, al tiempo que reconoce con perspicacia también los atributos impredecibles y potencialmente perturbadores del enunciado en la vida

Political Theory, p. 36 y 138.

${ }^{33}$ Pajnik, "Feminist Interpretations", op. cit. 
cotidiana. ${ }^{34}$ De hecho, Habermas defiende la revelación de la particularidad que hace posible que el sujeto (ahora [?] descentrado) "dé testimonio de la posibilidad de no decir" a la identidad que ha proyectado en el otro, a pesar de lo que el sujeto tenga invertido en la identidad de este último. ${ }^{35}$

Todo esto es un logro importante, que apunta al compromiso de conversar -como una cuestión de comprensión y de vida- en mundos conflictivos formados por sujetos heterogéneos, sujetos que militan en contra de ser contenidos con indolencia dentro de los límites seguros del yo y del otro. Enfocadas de este modo, las formulaciones de Habermas podrían incluso ayudar a nuestra propia declaración de inmanencia. Una afirmación de la inmanencia en lugar del triunfo de una racionalidad trascendental legisladora, que somete a todos los actores, a cada mundo y a todos los demás a la misma razón adjudicadora del sujeto soberano. Una vez más, las posibilidades que están en juego tienen que ser extraídas de la forma en que el pensamiento del filósofo habita el mundo -o se hace hacerlo- como anuncio de la inmanencia.

Sin embargo, en el momento de reconocer tales posibilidades, consideremos también la otra cara del razonamiento de Habermas sobre la deliberación y el diálogo, que implica el enunciado y el otro. Lo más importante es la preocupación de que las consideraciones del filósofo sobre estas cuestiones aparezcan como "típicamente ensombrecidas por el carácter normativo preciso en exceso de la obligación" que Habermas considera que contrae el yo. ${ }^{36}$ Se trata de una jugada que en sí misma está relacionado con su creencia en un consenso ulterior. ${ }^{37}$ De hecho, las propuestas más amplias de Habermas con respecto al otro y a la argumenta-

${ }^{34}$ Habermas, Philosophical Discourse of Modernity, op. cit., pp. 321-26; White, Sustaining Affirmation, op. cit., p. 37.

${ }^{35}$ Habermas, Theory of Communicative Action, op. cit., p. 399.

${ }^{36}$ White, Sustaining Affirmation, op. cit., p. 36.

${ }^{37}$ Habermas, Knowledge and Human Interests, op. cit., p. 314; Habermas, Philosophical Discourse of Modernity, op. cit., p. 311. 
ción no pueden quedar al margen de su "afirmación subyacente de que una orientación al consenso está incorporada al telos del lenguaje". ${ }^{38}$ Esto nos lleva al carácter a menudo excluyente, intranquilamente apriorístico e inestablemente despolitizador de las promulgaciones del filósofo sobre la comunicación y el consenso, lo intersubjetivo y lo no coercitivo, y el lenguaje y la razón. La escolástica ataca de nuevo.

Todo esto tiene implicaciones, a fin de cuentas, para el llamamiento de Habermas a una modernidad autocrítica, cuyo valor en nuestros tiempos de furiosos nacionalismos-populismos autoritarios, gubernamentales y musculosos sería un descaro ignorar. Sin embargo, al mismo tiempo, las propuestas del filósofo son sostenidas y reprendidas por su colusión a priori de la modernidad y Europa, de modo que ambas entidades-conceptos aparecen como hecho histórico, metáfora teórica y abstracción analítica. Aquí, no sólo se ensaya Occidente como modernidad, sino que se escenifica la modernidad "como Occidente". ${ }^{39}$

$\mathrm{Al}$ mismo tiempo, lejos de encasillar simplemente la escritura de Habermas como eurocéntrica, tal reconocimiento implica de manera importante entrar en los protocolos relacionados del pensamiento del filósofo. En tales procedimientos, no se trata tan sólo de una escisión de lo no occidental, sino más bien de una historia de Europa modelada, atenuada e idealizada que en sí misma apuntala la teoría crítica de la modernidad de Habermas. Dicha idealización marca la historia de la nación (occidental) de Habermas, tal y como ha desentrańado con habilidad -el autodenominado "Habermasiano crítico"- Craig Calhoun. ${ }^{40}$ Se

${ }^{38}$ White, Sustaining Affirmation, op. cit., p. 36. Consideremos ahora otra afirmación de Habermas: "el uso del lenguaje con una orientación para alcanzar el entendimiento es el modo original del uso del lenguaje, sobre el cual el entendimiento indirecto, el dar algo para entender o el dejar que se entienda algo, y el uso instrumental del lenguaje en general, son parasitarios". Habermas, Theory of Communicative Action, op. cit., p. 288 (énfasis en el original).

${ }^{39}$ Timothy Mitchell, “The Stage of Modernity”, p. 15 (énfasis en el original).

${ }^{40}$ Calhoun, "Class-consciousness of Frequent Travelers", op. cit., pp. 319-320. 
extienden a las formas en que la concepción de Habermas de la esfera pública liberal presenta una historia idealizada de las esferas públicas burguesas liberales, negándose a admitir las tradiciones plurales de intercambio razonado que marcaron la Europa occidental del siglo xviII. De este modo, ignora cómo el público burgués se apropió y marginó esas nociones más inclusivas de participación y debate público, cerrando de manera estratégica el abanico de posibles interlocutores. ${ }^{41}$ En este sentido, resultan especialmente conmovedoras las críticas feministas sobre el hecho de que la oclusión de las mujeres en la esfera pública burguesa no fue un mero accidente, sino que estas esferas públicas, tal y como las relata Habermas (y otros), se constituyeron de forma aguda a partir de estas exclusiones de género. 42

Partiendo de estos debates, me gustaría sugerir que lo que está en juego no son meros errores de comprensión, analíticos y empíricos. Más bien, tales proyecciones idealizadas de la historia y la sociedad tienen una profunda procedencia, amplias implicaciones. Consideremos ahora la propuesta de Habermas de que, bajo la modernidad, la noción de mundo "nuevo" o "moderno" pierde un "significado meramente cronológico" para asumir, en cambio, "el significado opositor de una era enfáticamente 'nueva". ${ }^{43}$ Esto significa, además, que para el filósofo el orden normativo de la modernidad tiene que fundarse en sí mismo, en lugar de extraer sus disposiciones de los modelos ofrecidos por otras épocas, por supuesto anteriores.

${ }^{41}$ Bourdieu, Pascalian Meditations, op. cit., pp. 65-66; Craig Calhoun (ed.), Habermas and the Public Sphere.

${ }^{42}$ Nancy Fraser, "Rethinking the Public Sphere: A Contribution to the Critique of Actually Existing Democracy"; Joan B. Landes, Women and the Public Sphere in the Age of the French Revolution; y Pajnik, "Feminist Interpretations", op. cit. Vid. además, Fleming, "Women and the 'Public Use of Reason", op. cit:; Johanna Meehan (ed.), Feminists Read Habermas: Gendering the Subject of Discourse; Dena Goodman, "Public Sphere and Public Life: Toward a Synthesis of Current Historiographical Approaches to the Old Regime".

${ }^{43}$ Habermas, Philosophical Discourse of Modernity, op. cit., p. 5. 
Ahora bien, como he argumentado antes, se ofrece una representación idealizada que es a la vez persuasiva y agudamente representativa. ${ }^{44}$ De hecho, a pesar de sus propias distinciones, las formulaciones de Habermas forman parte de interpretaciones más amplias de la modernidad que han supuesto una interacción incesante entre los atributos ideales y las manifestaciones reales del fenómeno. Esto ha significado no sólo que lo real ha sido aprehendido en términos de lo ideal, sino que incluso cuando se reconoce una brecha entre ambos, lo real (de la modernidad) es visto como tendiendo hacia lo ideal (de la modernidad) con cada uno apuntalando al otro. Aquí, son justo las mezclas de las articulaciones reales y las proyecciones idealizadas de la modernidad las que han definido sus dimensiones mundanas. En conjunto, estos procedimientos, que anuncian mapeos jerárquicos del tiempo y el espacio, no nada más ordenan el mundo, sino que lo constituyen en realidad, de modo que las propuestas de Habermas participan en la mundificación de la modernidad, como parte de (en última instancia) un intento de adjudicación con el objetivo de redimir, llevar a término, el proyecto inacabado de la Ilustración. ${ }^{45}$

Las preguntas clave que se plantean son las siguientes: ¿Qué está en juego al entrar de forma crítica pero cuidadosa en los protocolos del pensamiento de Habermas? ¿Podría tal medida revelar los límites de principalmente lamentar, y luego refutar con facilidad la ausencia en la teoría eurocéntrica "clásica" de lo no occidental y del imperio? ¿Nuestras afirmaciones y críticas de este tipo circunscriben de forma diversa las lecturas críticas del pensamiento europeo, sus problemas y sus potencialidades, como si se tratara de una apuesta mutua? ¿Podríamos rastrear, en cambio, la omnipresente subordinación de lo inmanente, lo afectivo, lo

\footnotetext{
${ }^{44}$ Dube, Subjects of Modernity, op. cit., pp. 70-73.

${ }^{45} \mathrm{He}$ analizado más a fondo estas cuestiones en relación con la obra de historiadores intelectuales de Europa como Reinhart Koselleck y Hans Ulrich Gumbrecht en Dube, After Conversion, op. cit. Vid. también Dube, Subjects of Modernity, op. cit.
} 
cotidiano, lo extraanalítico, lo mundano a los imperativos de una razón escolástica, una racionalidad adjudicadora? ¿No debería llevarse a cabo este cuestionamiento en los mundos más amplios -no occidental y occidental, cotidiano y académico, subalterno y de elite-? ¿No hay una cierta conmoción, incluso un patetismo, que se encuentra cuando se piensa a través de protocolos académicos -como los de Habermas- que intentan reconocer y declarar la diferencia, pero que en exclusiva pueden hacerlo volviendo a un "debería" escolástico decididamente singular? ¿No es premonitorio que nos encontremos ante la legislación del sentido y la ordenación de la vida que rehace el mundo, no sólo a través de retículas modulares, sino a imagen y semejanza?

\section{Segundo tema}

Hace dos décadas, en un taller sobre historiografía moderna en la Ciudad de México, un estudiante de posgrado planteó una pregunta sobre la necesidad de especificar qué es con exactitud lo que está en juego al discutir la historia como algo que siempre aparece en la imagen de la modernidad. El ponente, una futura estrella académica, se limitó a mirar hacia otro lado. En medio del estudiado silencio, la condescendencia era palpable. Mientras muchos de los compañeros del estudiante y varios académicos certificados se reían, incluso los que simpatizaban con la consulta y su espíritu miraban hacia los dedos de los pies avergonzados. Se trataba de una lección pública sobre el requisito no declarado de no dudar nunca de las doxas, que se engendran a sí mismas, como efecto y afecto de los derechos analíticos, las jerarquías cotidianas y su reproducción rutinaria en los escenarios académicos.

Incapaz de contenerme, replanteé la importancia de la pregunta del estudiante, haciendo hincapié en la necesidad de abordar al menos el acoplamiento de la escritura de la historia y la nación bajo los regímenes de la modernidad y sus imaginarios. El orador parecía 
inquieto, pero estaba a punto de responder cuando un historiador muy veterano, un venerable mandarín, tomó el micrófono. En su calidad no sólo de estimado presidente de la sesión, sino también de deidad presidenta del taller -y mecenas de varios historiadores de varias generaciones-, este don y decano entre los eruditos, se dirigió magistralmente a la audiencia. Cuestionar la modernidad, la nación y la escritura de la historia, dijo, es cosa de las nuevas teorías "postmodernas" y "postcoloniales". El verdadero historiador trabaja con diligencia en los archivos, lejos de tales especulaciones. Sin embargo, todo lo que dijo el estimado historiador sobre el propósito único de la investigación sin valores en los archivos estatales reprodujo la suposición común sobre la nación moderna y su historiografía como la marcha incesante del progreso. En este caso, cuanto más se separa la escolástica de lo mundano y de lo teórico, más tropieza con su desorden, con su complicidad con los imaginarios rutinarios del Estado y del desarrollo.

Dos semanas más tarde, me encontraba hablando en los coloquios semanales de un distinguido departamento de una famosa universidad. Un poco receloso, me basé en mi construcción más amplia de una historia etnográfica de una comunidad "intocable" para plantear cuestiones sobre la interacción entre casta y poder, mito e historia, y los encantos de los símbolos de gobierno del Estado moderno y las fabricaciones de legalidades religiosas por parte de las comunidades subalternas. Al final, también eché mi red algo más amplia. Aprovechando los materiales etnográficos e históricos, expuse las implicaciones de mi análisis para la persistencia de las antinomias rutinarias - de la modernidad y la tradición, el Estado y la comunidad, la racionalidad y el ritual, y la razón y la emoción- dentro de influyentes corrientes de la teoría social y política en contextos occidentales y no occidentales.

Durante el debate, un académico vanguardista, portador de la antropología de vanguardia, me planteó una pregunta de lo más amable. Me preguntó sobre la forma en que mi trabajo se 
relacionaba con el estudio de los grupos de castas inferiores e intocables, que el académico subrayó que era el verdadero ámbito, el campo real de mi investigación. En respuesta, expuse algunas de las continuidades y diferencias entre mi trabajo y otros estudios sobre las comunidades dalit. Sin embargo, también hice hincapié en que las cuestiones críticas de los mitos y la creación de la modernidad, la oralidad y la construcción de historias, y la escritura y la formación de tradiciones eran asimismo las áreas/campos de mi investigación. ${ }^{46}$ Fue un intercambio totalmente civilizado. Sin embargo, ese ir y venir me ha acompañado en los años posteriores.

Estaba en juego una distinción clave, basada en el derecho académico y la jerarquía académica, entre el "es" y el "debe". En este caso, el estudio de los grupos dalit y subalternos realizado por un historiador más joven aparecía como una condición inherente a los límites de una investigación teórica más amplia: el "es" ineludible del esfuerzo académico. Por el contrario, un estatus más elevado lo ocupaba la labor intelectual de analistas consumados, que realizaban investigaciones en lugares etnográficos con múltiples emplazamientos, iniciados en la teoría, y que no se veían limitados por "áreas" asfixiantes, que es lo que (nos decían) debía ser la reflexión crítica. La escolástica tiene muchos matices.

\section{Suturas finales}

A pesar de los hábiles esfuerzos de los dos distinguidos profesores (junto con los esfuerzos de otros), he sido incapaz de abandonar mis hábitos, que giran en torno a conjunciones de narrativa y teoría. Hace alrededor de una década y media, articulando legalidades/ilegalidades cotidianas, culturas coloniales y una modernidad evangélica -y cuestiones de significado, poder y diferen-

\footnotetext{
${ }^{46}$ Saurabh Dube, Untouchable Pasts: Religion, Identity, and Power among a Central Indian Community, 1780-1950.
} 
cia, muy ampliamente- defendí una historia sin garantía. ${ }^{47}$ Aquí se encuentran los procedimientos que participan en esfuerzos críticos más amplios y continuos que insinúan un "reciente cambio ontológico" en la teoría contemporánea, "el resultado de una creciente propensión a interrogar con mayor cuidado aquellas 'entidades' presupuestas por nuestras formas típicas de ver y hacer en el mundo moderno". ${ }^{48}$ Apoyándose en tales disposiciones, una historia sin garantía piensa en la garantía del progreso bajo la modernidad, interrogando con minucia los escándalos de Occidente y de la nación, emprendiendo tales tareas de forma solapada.

Por un lado, las concepciones, las proposiciones y los atropellos cuestionados por una historia sin garantía se entienden como condiciones agudas de conocimiento, entidades y coordenadas que apuntalan los mundos que habitamos, exigiendo una articulación crítica. Por otro lado, precisamente ese reconocimiento aprende pero se diferencia de las perspectivas anti y postfundacional, de manera que hay un cierto desplazamiento de "la carga intelectual desde la preocupación por lo que se opone y deconstruye", hasta comprometerse asimismo con "lo que debe ser articulado, cultivado y afirmado a su paso". ${ }^{49}$ En conjunto, las disposiciones de una historia sin garantía están íntimamente ligadas a los términos de una "ontología débil", reconociendo a la vez el carácter discutible y contingente y la naturaleza inevitable $y$ necesaria de las concepciones constitutivas del yo, del otro y del mundo.

En primer lugar, los procedimientos de una historia sin garantía se acercan a lo "universal" y a lo "particular" a través de la atención a sus vinculaciones compartidas y producciones mutuas, así como a sus exclusiones fundantes y contradicciones constitutivas. En segundo lugar, aquí se encuentran las disposiciones hacia la interrogación prudente y la afirmación crítica, cada una de las cuales

\footnotetext{
${ }^{47}$ Dube, Stitches on Time, op. cit.; vid. también, Dube, After Conversion, op. cit.; y Dube, Subjects of Modernity, op. cit.

${ }^{48}$ White, Sustaining Affirmation, op. cit., pp. 4-5.

${ }^{49}$ Ibidem, p. 8.
} 
está siempre abierta a la revisión. En tercer lugar, estos protocolos permiten considerar cuidadosamente las categorías conceptuales de procedencia académica al ponerlas en relación con las configuraciones cotidianas de estas entidades. Por último, de este modo, una historia sin garantía atiende a los supuestos, categorías y entidades que apuntalan mundos y sujetos, haciendo palpable un pensamiento a través de la modernidad y sus márgenes, siempre permaneciendo con los escándalos de Occidente y la nación..$^{50}$

Me gustaría sugerir ahora que mi énfasis en la inmanencia desplaza los términos de una historia sin garantía de manera específica. De hecho, el reconocimiento explícito y la articulación, tanto en el trabajo como en la vida, de lo afectivo y lo encarnado, lo experiencial y lo extraanalítico, lo cotidiano y lo mundano -es decir, de lo inmanente-como algo que recorre los mundos sociales, tiene consecuencias críticas. En primer lugar, a pesar de su afirmación de lo ontológico, el anterior elenco un tanto cerebral de una historia sin garantía se hace ahora de carne, hueso y espíritu. En segundo lugar, las propias categorías (académicas y sociales) se presentan menos como dispositivos explicativos principalmente instrumentales y mucho más como atributos constitutivos de los mundos sociales, que a menudo y de forma diversa tienen propiedades de valor, invitando e incitando a prácticas significativas. Por último, el énfasis anterior de una historia sin garantía en lo que respecta a la pregunta prudente y la afirmación crítica de los mundos sociales adquiere ahora una mayor inmediatez e indeterminación, interrumpida por lo incierto, lo misterioso y lo inimaginable. Si la verdad es una cuestión de apuesta, una apuesta que uno hace consigo mismo, como argumentó en su día Merleau Ponty, es porque la verdad tiene que ver con la vida y el vivir, la política y los mundos, cada uno de los cuales apuesta por el otro. Se trata de mundos vitales, saturados de inmanencia, que nos corresponde cues-

${ }^{50}$ White, Sustaining Affirmation, op. cit., p. 8. Dube, Stitches on Time, op. cit.; Dube, After Conversion, op. cit.; y Dube, Subjects of Modernity, op. cit. 
tionar a conciencia, articular éticamente e incluso reencantar en medio de los encantos que abundan. Éste podría ser el caso, en particular, cuando pensamos en el derecho y el privilegio, justo para desaprender de modo activo el privilegio y el derecho.

\section{Al FINAL}

Todo esto es para preguntar también si ciertas cuestiones clave simplemente desaparecen cuando reconocemos la presencia de la inmanencia en medio de los encantos de la modernidad. ¿Qué está en juego al preguntar si la más cuidadosa y creativa de "nuestras" comprensiones podría subsumir y subordinar -a nuestras convincentes afirmaciones- mundos contradictorios con sus conflictos? Al responder política y afectivamente a la urgencia del presente, ¿¿debemos abandonar el impulso de sondear con cautela y afirmar con sentido crítico los mundos sociales con el deseo de narrarlos cuidadosamente y describirlos con rigor? Tomando en serio los requisitos de las pruebas y la fidelidad a los hechos, ¿podríamos considerar también el tamizado de las pruebas a través de filtros críticos y la interpretación de hechos, tiempos y espacios inesperados? ¿Pueden estos hechos hablar con los ecos inquietos de la duda limitante en lugar de tratar a la ligera con certezas satisfactorias?

Bibliografía

Ahmed, Sara. The Cultural Politics of Emotion, Edimburgo, Edinburgh University Press, 2004.

Bauman, Zygmunt. Intimations of Postmodernity, Londres, Routledge, 1992. Bentancor, Orlando. The Matter of Empire: Metaphysics and Mining in Colonial Peru, Pittsburgh, University of Pittsburgh Press, 2017.

Bilgrami, Akeel. Secularism, Identity, and Enchantment, Cambridge, Mass., Harvard University Press, 2014, p. 183. 
. "Understanding Disenchantment", disponible en $<$ http://blogs. ssrc.org/tif/2010/09/06/disenchantment/>, 2010 (fecha de último acceso: 27/02/2018).

Bourdieu, Pierre. Distinction: A Social Critique of the Judgement of Taste, tr. Richard Nice, Cambridge, Mass., Harvard University Press, 1984.

. Language and Symbolic Power, tr. Gino Raymond y Matthew Adamson, Cambridge, Polity Press, 1991. 2000.

Calhoun, Craig. "The Class-consciousness of Frequent Travelers: Toward a Critique of Actually Existing Cosmopolitanism”, en Saurabh Dube (ed.), Enchantments of Modernity: Empire, Nation, Globalization, Londres, Routledge, 2010, pp. 310-340.

(ed.). Habermas and the Public Sphere, Cambridge, MA, MIT Press, 1992.

Clough, Patricia Ticineto y Jean Halley (eds.). The Affective Turn: Theorizing the Social, Durham, Duke University Press, 2007.

Dube, Saurabh. After Conversion: Cultural Histories of Modern India, New Delhi, Yoda Press, 2010.

- El archivo y el campo: Antropología, historia, modernidad, Ciudad de México, El Colegio de México, 2019.

- Stitches on Time: Colonial Textures and Postcolonial Tangles, Durham, Duke University Press, 2004.

- Subjects of Modernity: Time-Space, Disciplines, Margins, Manchester, Manchester University Press, 2017.

. Untouchable Pasts: Religion, Identity, and Power among a Central Indian Community, 1780-1950, Albany, NY, State University of New York Press, 1998.

(ed.). Modern Makeovers: Handbook of Modernity in South Asia, Nueva Delhi y Nueva York, Oxford University Press, 2011.

- Enchantments of Modernity: Empire, Nation, Globalization, London, Routledge, 2010.

Dube, Saurabh e Ishita Banerjee-Dube (eds.). Unbecoming Modern: Colonialism, Modernity, Colonial Modernities, 2a. ed. con nueva introducción, Londres/Nueva Delhi, Routledge/Social Science Press, 2019,

Fabian, Johannes. Out of Our Minds: Reason and Madness in the Exploration of Africa, Berkeley, University of California Press, 2000. 
Fleming, Marie. "Women and the 'Public Use of Reason"” en Johanna Meehan (ed.), Feminists Read Habermas: Gendering the Subject of Discourse, Nueva York, Routledge, 1995, pp. 117-137.

Fraser, Nancy. "Rethinking the Public Sphere: A Contribution to the Critique of Actually Existing Democracy", en Craig Calhoun (ed.), Habermas and the Public Sphere, Cambridge, MA, MIT Press, 1992, pp. 109-142.

Goodman, Dena. "Public Sphere and Public Life: Toward a Synthesis of Current Historiographical Approaches to the Old Regime”, History and Theory, núm. 32, 1992, pp. 1-20.

Habermas, Jürgen. Knowledge and Human Interests, tr. J. Shapiro, Boston, Beacon Press, 1971).

- Postmetaphysical Thinking: Philosophical Essays, tr. William Mark Hohengarten, Cambridge, MA, MIT Press, 1992.

The Philosophical Discourse of Modernity: Twelve Lectures, tr. Frederick G. Lawrence, Cambridge, MA, MIT Press, 1987.

. The Theory of Communicative Action, tr. T. McCarthy, 2 vols, Boston, Beacon Press, 1984.

Landes, Joan B. Women and the Public Sphere in the Age of the French Revolution, Ithaca, NY, Cornell University Press, 1993.

Mahmood, Saba. Politics of Piety: The Islamic Revival and the Feminist Subject, Princeton, Princeton University Press, 2011.

Mazzarella, William. "Affect: What is it Good for?" en Saurabh Dube (ed.), Enchantments of Modernity: Empire, Nation, Globalization, Londres, Routledge, 2010.

McCarthy, Thomas. "Introduction", en Jürgen Habermas, The Philosophical Discourse of Modernity: Twelve Lectures, tr. Frederick G. Lawrence, Cambridge, MA, MIT Press, 1987, pp. vii-xvii.

Meehan Johanna (ed.). Feminists Read Habermas: Gendering the Subject of Discourse, Nueva York, Routledge, 1995.

Mitchell, Timothy. "The Stage of Modernity", en Timothy Mitchell (ed.), Questions of Modernity, Minneapolis, University of Minnesota Press, 2000.

Mitchell, W. J. T. What do Pictures Want? The Lives and Loves of Images, Chicago, IL, University of Chicago Press, 2005.

Pajnik, Mojca. "Feminist Interpretations of the Public in Habermas's Theory (FEMINISTICNE INTERPRETACIJE JAVNOSTI V HABERMASOVI TEORIII)", Javnost - The Public, Slovene Supplement, 13, 2006, pp. 21-36. 
"Feminist Reflections on Habermas's Communicative Action:

The Need for an Inclusive Political Theory", European Journal of Social Theory, vol. 9, núm. 3, 2006, pp. 385-404.

Pieper, Josef. Scholasticism: Personalities and Problems of Medieval Philosophy, South Bend, Indiana, St. Augustine's Press, 2001.

Rancière, Jacques. The Ignorant Schoolmaster: Five Lessons in Intellectual Emancipation, tr. Kristin Ross, Stanford, Stanford University Press, 1991.

. The Nights of Labor: The Workers' Dream in Nineteenth-Century France, tr. John Drury, Philadelphia, Temple University Press, 1989.

. The Philosopher and His Poor, tr. Andrew Parker, Corrine Oster y John Drury, Durham, Duke University Press, 2004.

Rajchman, John. "Introduction”, en Gilles Deleuze (ed.), Pure Immanence: Essays on a Life, Nueva York Zone, 2001.

Stewart, Kathleen. Ordinary Affects, Durham, Duke University Press, 2007. van Roermund, Bert. "Kelsen, Secular Religion, and the Problem of Transcendence", Netherlands Journal of Legal Philosophy, vol. 2, núm. 44, 2015, pp. 100-115.

White, Stephen K. Sustaining Affirmation: The Strengths of Weak Ontology in Political Theory, Princeton, Princeton University Press, 2000. 